\title{
Developers of Ecological Site Description Find Benefits in Diverse Collaborations
}

\author{
By Jamin Johanson, and Maria Fernandez-Gimenez
}

\section{On the Ground}

- Ecological site descriptions (ESDs) are intended to provide the best available information relevant to a particular type of land and therefore should draw on multiple sources of information and expertise.

- We surveyed participants from 16 interagency ESD projects to understand better the process, benefits, challenges, and keys to success for collaborative ESD development.

- Collaborative ESD development involves federal and state agencies, universities, nongovernmental organizations, private landowners, and consultants and provides perceived benefits that greatly outweigh the challenges.

- The results of this study may improve the transparency and credibility of ESD development by encouraging the inclusion of diverse stakeholders.

Keywords: interagency, interdisciplinary, collaborative, ESD development.

Rangelands 37(1):14-19

doi: 10.1016/j.rala.2014.12.003

(c) 2015 The Society for Range Management

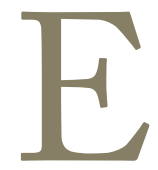

cological site description (ESD) development should involve a broad array of experts. Range science is an inherently integrative discipline, drawing from related disciplines, such as soil science, ecology, animal science, and biology, to name just a few. The interdisciplinary nature of rangeland ecology and management is exemplified by the emergence of ESDs as fundamental references for decision making and research. ESDs summarize and compare the relative importance of soils, climate, hydrology, and physiography in determining the potential vegetation, disturbance regimes, and community dynamics of distinctive rangeland types. ${ }^{1}$ Not only are ESDs used to distinguish land types based on site potential, but they also include interpretations for wildlife, livestock, hydrology, and various ecosystem products as well as services associated with a specific ecological site. ${ }^{2}$ The state-and-transition model (STM) included in each ESD, when based on sound information, can be particularly useful for integrating information across disciplines and evaluating the effects of ecological change. ESDs are increasingly considered a common currency for land interpretations among agencies and disciplines. ${ }^{3}$

The ESD information system serves as an on-line reference library intended to put the best available information, relevant to a particular type of land, into the hands of end users. ${ }^{4}$ Indeed, the ESD information system holds great promise to help bridge the gap between science (generation of information) and management (application of information), especially when managers and scientists come together to coproduce the knowledge included in ESDs. Processes of knowledge coproduction are gaining acceptance in ecological and conservation disciplines as the benefits of engaging multiple knowledge holders are recognized. ${ }^{5}$ Yet the process of developing ESDs that effectively capture, organize, and deliver high-quality information from multiple disciplines and stakeholders is not well understood.

\section{Challenges and Questions}

The task of integrating information across disciplines is complicated by the diversity of data types and sources, the complexity of natural systems, the involvement of the right people in the right ways, and the sheer scope of describing many thousands of different land types individually. Moreover, the general lack of research and monitoring data in many places necessitates the use of professional and local knowledge in ESD development, which suggests that no individual person, agency, or discipline can adequately develop ESDs without substantial inputs from a diversity of collaborative partners. Further, interviews with STM creators and users, ${ }^{6}$ as well as a recent review of STMs in the Ecological Site Information System database, ${ }^{7}$ raise concerns about the consistency of STM development approaches and terminologies and the potential overemphasis on grazing as the dominant process and livestock production as the major 
service depicted in many current STMs. Involving end users in the ESD development process, as well as scientists and professionals, has been shown to augment scientific understanding with local knowledge, increased awareness, and "buy-in" of ESDs and STMs as valuable management resources and to increase the likelihood of their use to guide assessment, management, and monitoring of rangelands. ${ }^{8}$ Bringing diverse disciplines together may also help to broaden the focus of STMs to consider other disturbance regimes, management practices, and ecosystem benefits (Fig. 1).

In an effort to understand better the process of collaborative ESD development, we surveyed individuals currently involved in interagency and interdisciplinary projects that include some aspect of ESD development. The guiding questions of this research are: 1) Who participates in collaborative ESD development and what roles do they play? 2) What tangible outputs do these collaborative groups produce? 3) What are the perceived benefits, challenges, and keys to success of collaborative ESD projects? and 4) How can we increase the occurrence and effectiveness of collaborative ESD development for improved ESD products in the future?

\section{Our Survey}

We identified as many interagency and interdisciplinary ESD development projects as possible through e-mail solicitations to known ESD leaders and developers. Some of the projects we identified represent formal interagency agreements, whereas others represent informal collaborative efforts. We sent a short questionnaire containing open-ended (qualitative) and closed-ended (quantitative) questions to participants in 16 different projects and asked the recipients to forward the survey to others involved in collaborative ESD projects (i.e., snowball sample). By January 2013, we had received 23 survey responses representing 16 different collaborative ESD development projects. Quantitative responses were summarized as frequencies, and qualitative responses were coded and synthesized for common themes.

It is important to note that these results do not provide an objective assessment of the quality or credibility of the ESDs that resulted from the collaborative processes included in the survey. However, the results objectively report the participants, roles, and tangible outputs of these processes as well as the respondents' subjective perceptions of the benefits and challenges of collaborative ESD development. Further, because we do not know how many collaborative ESD projects have taken place, we cannot assess how representative our sample is. Although the number of projects and respondents is small, the number of projects may represent a large proportion of collaborative ESD efforts.

\section{Who Is Involved?}

Current collaborative ESD development efforts involve federal and state agencies, universities, nongovernmental organizations (NGOs), and private landowners and consultants. The various groups tend to fill different roles in ESD development projects, as summarized in Table 1. The Natural Resources Conservation Service (NRCS), which has historically taken the lead in ESD development, is involved in all 16 of the collaborative ESD projects surveyed. The NRCS is typically involved in most aspects of collaborative ESD projects by fulfilling many of the project roles identified by the survey, with the exception of directly funding the projects. The Agricultural Research Service and researchers from various universities are each involved in 10 of 16 projects and fill similar roles by providing scientific knowledge and ecological site expertise. The Agricultural Research Service also provides data analysis and interpretation for the majority of the projects in which it is involved. The Bureau of Land

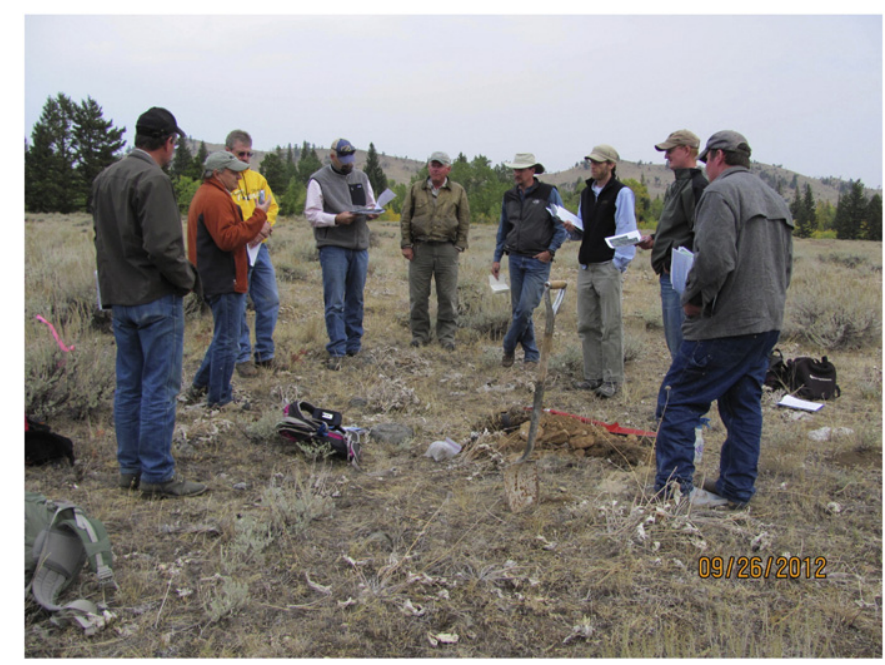

Figure 1. Interagency field discussion at an ecological site in Montana. Photo courtesy of Eva Muller. 
Management (BLM) is participating in nine projects and provides access to existing datasets, professional knowledge, and local knowledge of the landscape.

The US Forest Service (USFS) is involved in less than half of the projects surveyed; however, of the seven projects in which it is involved, the USFS contributes to almost all of the roles identified by the survey. State agencies have partnered with six of the projects and provide mostly time, equipment, and funding. The National Park Service and US Department of Defense consistently provide funding for collaborative ESD development projects, with the Park Service also providing local knowledge of the area. Ranchers and land owners consistently provide local knowledge in ESD development projects. Of the remaining five groups identified in the surveys, only the United States Geological Survey (USGS) and NGOs consistently filled roles in the collaborative ESD development projects, with NGOs providing primarily knowledge and expertise and the USGS filling roles related to data collection and analysis.

The survey responses did not identify the areas of expertise of each project participant consistently, so they were not quantified. However, based on the respondents that did identify areas of expertise of group members and through some of the open-ended questions, it is apparent that some projects have contributors from diverse disciplines, whereas other projects have contributors who are mainly from the range profession and represent various agencies.

\section{What Are the Products?}

Each of the projects surveyed contributes explicitly to the ESD development effort in some way, but each has a different focus. A total of 14 projects refine the concepts of ecological site classifications. For STM development, a total of 13 projects describe ecological states, and 12 identify transition drivers and processes. The ecological interpretations and supporting information sections of ESDs are addressed by a total of 11 and 12 projects, respectively. Of the groups, 11 reported that they would actually be updating ESDs as part of the project. Other tangible outcomes of these projects are peer-reviewed publications, project reports, presentations, workshops, graduate degrees, and databases. It should be noted that many of these projects have goals and products unrelated to ESDs; however, these projects are being leveraged to improve the information in ESDs while meeting other research and management objectives.

\section{Benefits}

The open-ended portion of the survey revealed perceived benefits, challenges, and keys to success when working with interagency and interdisciplinary groups to develop ESDs (Table 2). Of the perceived benefits, improved working relationships and communication were the most common, with 12 mentions by 23 respondents. In one participant's words, the most important benefits of the collaborative ESD process were "Improved working relationships between USGS, BLM, and NRCS. Data-supported ESDs that are defensible, accepted, and lead to improved grazing management." As this quotation also suggests, an increase in application of ESDs in the field, in part owing to increased buy-in by diverse participants, was also a commonly perceived benefit, earning six mentions. As another respondent put it, "Buy-in by the local management community is an important component of this collaboration effort. Hopefully these ESDs will be used, critiqued, and revised through the years by the local land managers. This was also an excellent way to capture experience from ranchers and land managers who have been working in this area for decades."

Other perceived benefits that had multiple mentions are ESDs as a common currency for land management, improved data credibility, decreased conflict, and increased efficiency. The decrease in conflict and increase in efficiency were somewhat surprising benefits. We expected that involving more, and more diverse, people in creating ESDs might increase the likelihood of disagreement and slow down the process of ESD development. Instead, survey responses indicated that involving a diverse group in ESD development ultimately led to greater agreement and efficiency.

\section{Challenges}

The most common challenge cited had to do with datarelated issues, with seven mentions related to data quality, diversity, storage, and analysis. The "lack of an integrated, interagency database," "large databases and infrastructural needs," and "sharing large amounts of historic data" were all cited as major challenges to collaborative ESD efforts.

A second major challenge was coming to a unified understanding of key ESD concepts, project goals, and priorities. The following survey comments illustrate these challenges: "The biggest challenge was educating the core team on the components of state-and-transition models and translating that knowledge to field work"; "Differing ideas about what ecosites are among agencies. Differing priorities and goals among agencies"; "Many people in the wildlife research world are not familiar with ecological sites and thus are suspicious of their use in some projects."

Positive verification of ecological sites in the field was also mentioned as a challenge with ESD projects in general. Other common challenges were time and resource constraints and participant recruitment and consistent involvement. "Getting participants to attend a workshop [was a challenge].... Workshop probably not possible without National Park Service funding." When asked what they would do differently in similar projects in the future, common responses were to "start networking earlier" and/or "reach out to even more possible participants." 


\begin{tabular}{|c|c|c|c|c|c|c|c|c|c|c|c|c|c|c|c|}
\hline Agency or group & 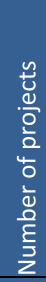 & 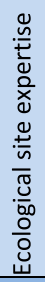 & 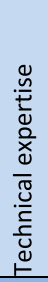 & 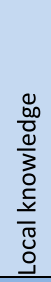 & 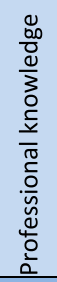 & 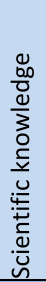 & 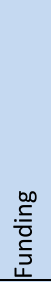 & 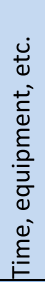 & 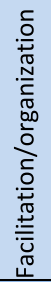 & 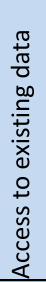 & 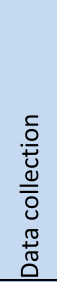 & $\begin{array}{l}\frac{n}{n} \\
\frac{n}{\pi} \\
\frac{\pi}{\pi} \\
\pi \\
\frac{\pi}{\pi} \\
\frac{\pi}{0}\end{array}$ & 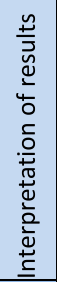 & 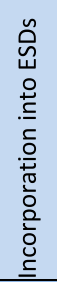 & 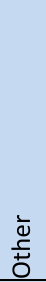 \\
\hline $\begin{array}{l}\text { Natural Resources } \\
\text { Conservation Service }\end{array}$ & 16 & 14 & 12 & 11 & 14 & 9 & 4 & 9 & 12 & 8 & 10 & 9 & 11 & 13 & 1 \\
\hline $\begin{array}{l}\text { Agricultural Research } \\
\text { Service }\end{array}$ & 10 & 7 & 5 & & 3 & 8 & 4 & 3 & 3 & 3 & 4 & 7 & 7 & 2 & \\
\hline Universities & 10 & 6 & 5 & 4 & 4 & 7 & 3 & 4 & 4 & 3 & 3 & 4 & 5 & 1 & 2 \\
\hline $\begin{array}{l}\text { Bureau of Land } \\
\text { Management }\end{array}$ & 9 & 1 & 2 & 5 & 7 & 3 & 3 & 4 & 4 & 5 & 2 & & 2 & 1 & \\
\hline U.S. Forest Service & 7 & 4 & 5 & 7 & 6 & 3 & 3 & 5 & 3 & 4 & 4 & 3 & 5 & 3 & \\
\hline State agencies & 6 & 1 & 2 & 3 & 3 & 1 & 4 & 4 & 3 & 2 & 3 & 2 & 3 & & \\
\hline National Park Service & 4 & & 2 & 3 & 2 & 2 & 3 & 1 & 1 & 2 & & & 1 & & \\
\hline Department of Defense & 3 & 1 & & 1 & 1 & 1 & 2 & 1 & 1 & 1 & & & & & \\
\hline Landowners/ranchers & 3 & & 1 & 3 & 1 & & & 1 & & 1 & & & 1 & & \\
\hline $\begin{array}{l}\text { Nongovernmental } \\
\text { organizations }\end{array}$ & 3 & 2 & 3 & 2 & 3 & 2 & & 1 & 1 & 1 & 1 & 1 & 3 & 1 & 1 \\
\hline Private contractors & 3 & & & 1 & 1 & & & & & 1 & & & & & \\
\hline US Geological Survey & 2 & 1 & 1 & & 1 & 1 & 1 & 1 & 2 & & 2 & 2 & 2 & & \\
\hline $\begin{array}{l}\text { US Fish and Wildlife } \\
\text { Service }\end{array}$ & 2 & 1 & 1 & 1 & 1 & 1 & & & & & & & & 1 & \\
\hline Other & 2 & 1 & & & 1 & 1 & 1 & 1 & & 1 & & & 1 & & 1 \\
\hline
\end{tabular}

\section{Keys to Success}

Survey respondents felt that communication, involving the right people, and aligning priorities were major keys to success in these projects. Effective communication, with nine mentions, was described as open, respectful, frequent, and that which "clearly identifies each partner's responsibilities, timelines, goals, etc." The importance of creating a group with diverse backgrounds and complementary strengths cannot be overstated. As one respondent put it, "I think all land managers within the project area need to be represented in the group.... Also, I wanted a diversified group, not just a bunch of range conservationists. I wanted soils folks, geology/hydrology experts, a biologist, a cultural resource specialist, local producers, etc. I thought the more diversity represented, the stronger the product." Having a leader that can "keep the ball rolling" and "focus the team" served to align goals and priorities and facilitate the success of the group in moving forward. Field visits (Fig. 2) were also considered very important for getting group members on the same page. "I also felt it was important to get all of these people out in the field looking and talking about things... This field time helped us when we came together for our group meetings" (Fig. 3). Keeping an open mind and "a willingness to try new approaches" was also a common key to collaborative success, as was support from management.

\section{Institutional Challenges}

The new Interagency Ecological Site Handbook for Rangelands ${ }^{9}$ outlines the formal need for interagency collaboration at the national, state, and local levels for the BLM, NRCS, and USFS. The projects included in this survey serve as existing models for the local working groups outlined in the interagency handbook (Box 1). In addition, these existing workgroups show that other agencies and partners are valuable contributors to ESD development, and formal programs or agreements are not an essential prerequisite to effective collaboration. Regional and national interagency workgroups can also benefit from the knowledge gained in this study by understanding the benefits, challenges, and keys to success of local working groups as well as the potential for involving other agencies and groups in varying roles.

Survey respondents in this study report both increased efficiency and decreased conflict while producing what respondents perceived to be collaboratively developed and high-quality ESD products (Box 2). These results are likely owing to the open, frequent, and respectful communication characteristic of 


\begin{tabular}{|c|c|}
\hline \multicolumn{2}{|c|}{$\begin{array}{l}\text { Table 2. Frequencies of the most commonly } \\
\text { mentioned benefits, challenges, and keys to } \\
\text { success as identified by survey respondents. }\end{array}$} \\
\hline Benefits & Count \\
\hline Improved working relationships and communication & 12 \\
\hline Increased application of ESDs in the field & 6 \\
\hline Increased efficiency & 3 \\
\hline Decreased conflict among stakeholders & 3 \\
\hline ESDs as a common currency among agencies & 3 \\
\hline Increased data credibility/buy-in & 2 \\
\hline \multicolumn{2}{|l|}{ Challenges } \\
\hline Data-related issues (e.g., quality, storage, analysis) & 7 \\
\hline Unifying concepts, priorities, and goals & 5 \\
\hline Time and resource constraints & 5 \\
\hline Participant recruitment and involvement & 3 \\
\hline Positive verification of ecological sites in the field & 3 \\
\hline \multicolumn{2}{|l|}{ Keys to Success } \\
\hline Effective and frequent communication & 9 \\
\hline Involving the right people in the right ways & 7 \\
\hline Aligning goals/priorities, effective leadership & 6 \\
\hline Group field visits & 4 \\
\hline Support from agency management & 2 \\
\hline Willingness to learn, try new things & 2 \\
\hline
\end{tabular}

successful working groups. Such communication clarifies objectives and perspectives, resulting in opportunities to leverage current programs and activities, reduce duplication of effort, and foster understanding among individuals with diverse backgrounds.

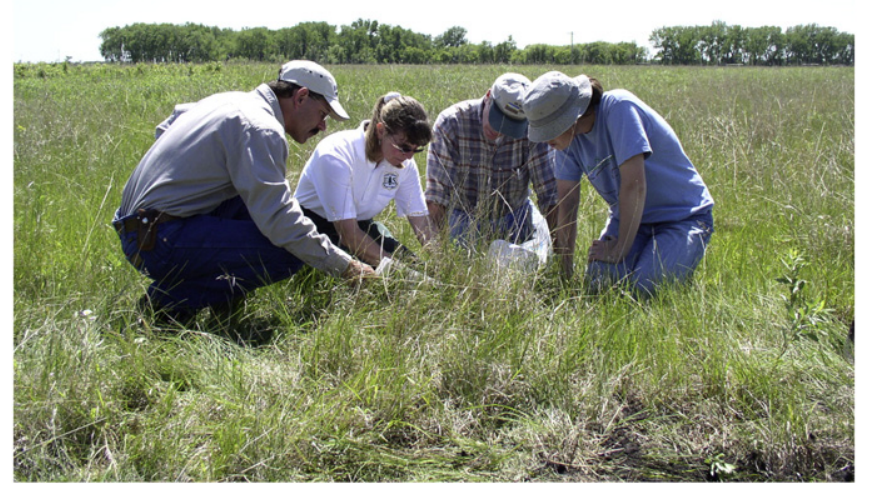

Figure 2. Interagency field discussion at an ecological site in North Dakota. Photo courtesy of Jeff Printz.

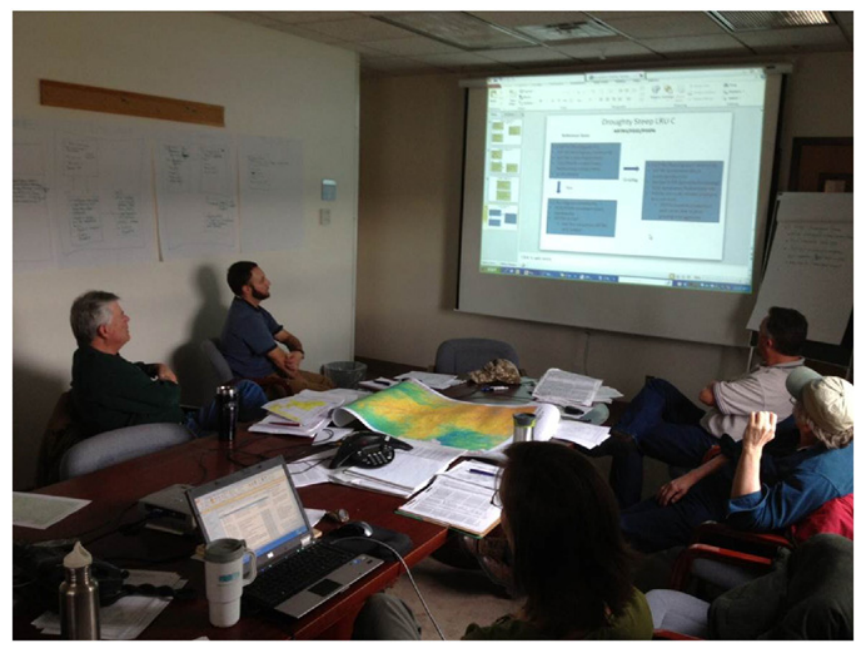

Figure 3. Synthesis of ideas and information involving multiple stakeholder groups at a state-and-transition modeling workshop. Photo courtesy of Kirt Walstad.

Box 1

Successful collaborative ESD development...

- Includes a wide array of experts,

- Clearly defines roles, goals, and responsibilities,

- Is supported by management,

- Involves clear, open, and frequent communication,

- Requires knowledge and resource sharing,

- And seeks to create ESDs with diverse applications.

Box 2

Collaborative ESD development was seen as...

- A good investment that increased efficiency,

- Producing both tangible and intangible outputs,

- Requiring significant time, resources, personnel, and the like,

- And ultimately increasing the quality, credibility, application, and adoption of ESDs.

Box 3

Continuing challenges include...

- Acquiring, storing, and integrating large quantities of diverse datasets,

- Building awareness of ESD and STM concepts among agencies, disciplines, and producers,

- Procuring sufficient financial, time, and personnel resources,

- And building collaborative capacity within and among agencies and disciplines. 
Given the perceived efficiencies of local collaborations, national and regional ESD leaders should institute policies and foster a culture ${ }^{10}$ that empowers ESD developers to communicate and collaborate effectively among agencies and disciplines. Sometimes this may be achieved best by encouraging grass-roots collaborations, such as many in this study, in lieu of institutionalized workgroups. Other times, collaborative workgroups may need to be agency-initiated and managed but may benefit from recruiting diverse members from other agencies, universities, and local knowledge holders.

There are persistent and universal challenges that need to be considered for ESD development efforts at all levels (Box 3). Current database issues limit our ability to acquire, store, and integrate large quantities of diverse data types. Conceptual understanding of ESDs and STMs across agencies and disciplines will require training geared toward differing audiences, such as producers, policy makers, and discipline specialists. In some cases, further investment in developing collaborative capacities in participating agencies and organizations is needed. And perhaps the most universal challenge of all will be the procurement of financial and human resources to sustain large-scale collaborative ESD-development projects.

\section{ESD Collaboration Moving Forward}

When asked whether they would participate in another collaborative ESD development project given the opportunity, $100 \%$ of those surveyed responded that they would. When asked if they would initiate a collaborative ESD project in the future, a surprising $91 \%$ responded that they would. The overwhelmingly positive experiences of those currently participating in interagency and interdisciplinary ESD projects bode well for the future of similar collaborations, which makes knowledge coproduction a more transparent and credible alternative for ESD development moving forward.

To survey respondents in this study, the process of integrating knowledge across agencies and disciplines is seen as a worthwhile investment of time and effort. This may in part be due to our inability to survey unsuccessful collaborations because failed teams do not stay together and are therefore difficult to identify and sample. However, based on the responses of teams that are working well together, we conclude that successful collaborative ESD development involves a wide array of experts-including scientists, professional specialists, managers, and producers-who communicate effectively and understand one another's roles. These teams must receive significant support from their various agencies to contribute effectively to the body of knowledge contained in ESDs. The results of this study suggest that those involved in the collaborative process perceive it as producing both tangible and intangible outcomes that ultimately improve the quality, credibility, relevance, and use of ESDs, often while leveraging the efforts of non-ESD programs and projects.

\section{References}

1. Аввотт L. 2014. ESDs: tools for teaching, tools for learning. Society for Range Management: Ecological Site Description Workshop Series, Workshop \#2: ESD Uses and Users. Available at http://www.rangelands.org/ESD/index.shtml. Accessed 2 May 2014 (Orlando, FL, USA).

2. NRCS. Natural Resources Conservation Service Ecological Site Information System. Available at https://esis.sc.egov.usda.gov/ (Accessed 1 August 2014).

3. Bestelmeyer, B. T., AND J. R. Brown. 2010. An introduction to the special issue on ecological sites. Rangelands 32:3-4.

4. BROWN, J. R., AND N. MACLEOD. 2011. A site-based approach to delivering rangeland ecosystem services. The Rangeland Journal 33:99-108.

5. Roux, D. J., K. H. Rogers, H. C. Biggs, P. J. Ashton, And A. SARGEANT. 2006. Bridging the science-management divide: moving from unidirectional knowledge transfer to knowledge interfacing and sharing. Ecology and Society 11:4.

6. Knapp, C. K., M. E. FernandeZ-Gimenez, D. D. Briske, B. T. Bestelmeyer, And X. B. Wu. 2011. An assessment of state-and-transition models: perceptions following two decades of development and implementation. Rangeland Ecology and Management 64:598-606.

7. Twidwell, D., B. W. Allred, and S. D. Fuhlendorf. 2013. National-scale assessment of ecological content in the world's largest land management framework. Ecosphere 4:1-27.

8. Knapp, C. N., M. E. FernandeZ-Gimenez, E. Kachergis, And A. RUDEEN. 2011. Using participatory workshops to integrate state-and-transition models created with local knowledge and ecological data. Rangeland Ecology and Management 64:158-170.

9. US Department of Agriculture-Forest Service and Natural Resources Conservation Service, US Department of the Interior, Bureau of Land Management. 2013. Interagency Ecological Site Handbook for Rangelands. 109 p. (Washington, DC, USA).

10. NorTon DL. 1976. Personal destinies: a philosophy of ethical individualism. Princeton, NJ, USA: Princeton University Press. $398 \mathrm{p}$.

Authors are Rangeland Specialist, Richfield MLRA Soil Survey Office, USDA Natural Resources Conservation Service, Richfield, UT 84701 (Johanson, jamin.johanson@ut.usda.gov); and Associate Professor, Dept of Forest, Rangeland and Watershed Sterwardship, Colorado State University, Fort Collins, CO 805241472 (Fernandez-Gimenez). 